\title{
Practice Enterprises - Key Enablers for the Development of Students' Entrepreneurial Skills: An FSQCA Approach
}

\author{
Daniela DAMIAN ${ }^{1}$ \\ Alexandru CAPATINA ${ }^{2}$ \\ Marilena RAPA ${ }^{3}$ \\ Gabriela CHIRU ${ }^{4}$
}

\begin{abstract}
Although active learning in practice enterprises is a well-known and widely used instructional method for entrepreneurial skills development, it remains a challenging issue to analyse how students immersed in practice enterprise learning journey developed their hard and soft skills and become interested in applying to startup funding programmes. In this study, a project-based storytelling approach is proposed to address two research propositions. Based on semi-structured interviews, the storytelling approach has been applied to a sample of 20 students involved in three practice enterprises from Faculty of Economics and Business Administration", Dunarea de Jos" University of Galati. All of them had previous experience in dealing with practice enterprises challenges, during their studies at the Economic College "Virgil Madgearu" of Galati. FsQCA methodology was employed to assess the causal conditions that led to students' success in entrepreneurial initiatives, built on their experiences with Simpract project (Transition from school to active life through internships and practice enterprises). The results show that the project-based active learning within practice enterprises enhanced the students' hard and soft entrepreneurial skills.
\end{abstract}

Keywords: active learning, entrepreneurship, practice enterprise, business skills

JEL classification: L26, M21

DOI: $10.24818 / \mathrm{RMCI} \cdot 2018.5 .476$

${ }^{1}$ Daniela Damian, „Dunarea de Jos” University of, Galati, Email:danah2030@yahoo.com, Telephone: 0740244635

2 Alexandru Capatina, „Dunarea de Jos” University of Galati, E-mail: alexcapatina@gmail.com, Telephone: 0723636396

${ }^{3}$ Marilena Rapa, Economic College „Virgil Madgearu” from Galati, Email: marilenarapa62 @ yahoo.com, Telephone: 0744509981

4 Gabriela Chiru, Economic College "Virgil Madgearu" from Galati, Email: gabriela chirugalati@yahoo.com, Telephone: 0726179691

476 Review of International Comparative Management

Volume 19, Issue 5, December 2018 


\section{Introduction}

The entrepreneurial education approaches of how students learn from their experiences within practice enterprises and business simulations has received very little attention, as most part of researchers have been focused on entrepreneurship encouragement models aiming at developing students' interest for entrepreneurship. Business simulation-based methods highlight that students have achieved what they were meant to achieve in terms of knowledge, skill development and other learning outcomes (Vos, 2015).

Bridging entrepreneurial active learning methods, the research framework exposes causal configuration of practice enterprises' learning outcomes, leading to development of hard and soft entrepreneurial skills and students' interest to apply for forthcoming start-up funding opportunities. The research involves narratives from 20 students from Faculty of Economics and Business Administration", Dunarea de Jos" University of Galati, who have been involved in three practice enterprises, in the fields of digital marketing, advertising and call-center. All of them had previous experiences in practice enterprises managed at the level of the Economic College "Virgil Madgearu" of Galati.

This paper is structured as follows: theoretical background reflects the knowledge base related to entrepreneurship education methods, with a focus on practice enterprises; the research methodology outlines why fsQCA is the appropriate method to explore the research framework; findings reveal the results of testing the two research propositions, by means of truth tables and QuineMcCluskey algorithm. The last part invites to reflection on the managerial implications of research results.

\section{Literature review}

Entrepreneurship education has the primary role to prepare the new generation of entrepreneurs, by offering students opportunities to learn in practice enterprise, business incubators and accelerators and developing their skills, to become creative, innovative, and entrepreneurial (Welsh et al., 2016).

The entrepreneurship education promotes the hard and soft skill development of prospective entrepreneurs to meet the challenges they face when they will launch a start-up. Entrepreneurship education involves mentorship support programmes, to immerse students in the entrepreneurial journey, from the opportunity recognition to market exploitation, along with knowledge of how to support a culture for creativity within teams and organizations (Gundry et al., 2014).

The Student Entrepreneurship Encouragement Model provides a complete overview of academic institutions' value propositions for students who express interest to apply to different start-up funding programmes or business incubators. The stages over which a business school can coordinate its entrepreneurial value 
proposition are the stimulation stage, the education stage, and the incubation stage (Jansen et al., 2015).

Carayannis and Von Zedtwitz (2005) present five incubator archetypes: the university incubator, the independent commercial incubator, the regional business incubator, the company-internal incubator, and the virtual incubator, this last one being the practice enterprise. Entrepreneurial education in practice enterprises and other active learning and training methods is associated with higher levels of entrepreneurship-related human capital assets, entrepreneurship-related knowledge and skills, positive perceptions of entrepreneurship, and students' interest to become an entrepreneur (Martin et al., 2013).

In the context of entrepreneurship education, practice enterprises enable students to capture fast-changing market opportunities in free-risk environments, endowing them with competencies to further act within the real business landscape (Esposito and Evangelista, 2014). Entrepreneurship education should be focused on call to action verbs like dream, create, explore, invent, and imagine. Entrepreneurship mentors must have the same innovative drive that is expected from entrepreneurship students (Kuratko, 2005) and guide students' entrepreneurial initiatives.

The impact of entrepreneurial simulations within practice enterprises is still poorly understood; the big advantage of practice enterprises training can be summarized as follows: students learn by experiencing small failures to build up resilience in the face of future real market conditions (Honig, 2004).

Learning by doing and experiential learning constitute appropriate incentives for developing the entrepreneurial know-how among students. Entrepreneurship educators and mentors' responsibilities lies in organising experiences through practice enterprises, internships and facilitating direct contacts with entrepreneurs, rather than giving a lecture on business models (Haase and Lautenschläger, 2011). An entrepreneurial university has the mission to engage students in as many as possible entrepreneurial projects, in close cooperation with the world outside the university (Blenker et al., 2008). Entrepreneurship education should consider the principles of Corporate Social Responsibility (Bibu, Nastase and Gligor, 2010) to better manage the expectations inside and outside the business schools (Nastase, Dobrea and Valimareanu, 2016).

\section{Research methodology}

Qualitative Comparative Analysis (QCA) methodology aims to bridge the gaps between quantitative and qualitative methods and explore the conditions that are necessary and/or sufficient for an outcome. Two core principles have been developed by the researchers who developed this method: equalfinality means that multiple pathways to achieve an outcome may coexist, while complex causality reveals that relationships across data are non-linear and non-probabilistic (Fiss, 2007; Woodside, 2014).

478 Review of International Comparative Management Volume 19, Issue 5, December 2018 
This research is built on the assumption that students' perceptions regarding the benefits of engaging in practice vary from one to another; thus, the conceptual model design resides on alternative combinations of causal conditions, related to two research propositions (equivalent of research hypotheses in quantitative studies).

We have sent personalized invitations to 20 students, involved in three practice enterprises from Faculty of Economics and Business Administration", Dunarea de Jos" University of Galati, to assess the drivers for the development of hard and soft entrepreneurial skills, and interest to apply for start-up funding programmes, on a scale from 1 (very low impact) to 10 (very high impact).

QCA method implies the fuzzy-set calibration to highlight the degrees to which the 20 cases from the research sample belong to a set, with intermediate membership levels. In this way, we transformed the values from the scale (1 to 10) in values ranging from 0.1 to 1 . We considered three qualitative anchors for the calibration: an anchor to define full membership, an anchor to define an almost complete lack of membership, and a crossover point (Ragin, 2008). Table 1 reflects the calibration scale, which will be further used for the causal conditions and outcome.

Table 1. Calibration scale

\begin{tabular}{|c|c|}
\hline Fuzzy-set value & Membership \\
\hline 1 & fully in \\
\hline 0.9 & \multirow{2}{*}{$\begin{array}{l}\text { mostly but } \\
\text { not fully in }\end{array}$} \\
\hline 0.8 & \\
\hline 0.7 & \multirow{2}{*}{ more or less in } \\
\hline 0.6 & \\
\hline 0.5 & cross-over: neither in nor out \\
\hline 0.4 & \multirow{2}{*}{ more or less out } \\
\hline 0.3 & \\
\hline 0.2 & \multirow{2}{*}{$\begin{array}{c}\text { mostly but } \\
\text { not fully out }\end{array}$} \\
\hline 0.1 & \\
\hline
\end{tabular}

(Adapted from Ragin, 2008)

Table 2 outlines the four antecedent conditions derived from Proposition 1, revealing four items addressed to the 20 students who has been involved in the practice enterprises (testing strategy in a free financial risk environment, opportunities to test alternative scenarios within a strategy, learning from failures and knowledge sharing between students), and the outcome: development of hard and soft entrepreneurial skills, as well as a new variable - CND (reflecting causal configurations of antecedent conditions) as the result of computing the fuzzy-set values of antecedent conditions, using fsQCA software. 
Table 2. Calibration of qualitative data from Proposition 1

\begin{tabular}{|c|c|c|c|c|c|c|c|}
\hline . & & & & & & & fsqca \\
\hline Variables & Case & Analyze & & & & & \\
\hline Case & & FFR & AST & LFF & KSH & HSS & CND \\
\hline & 1 & 0.6 & 0.8 & 1 & 0.9 & 0.9 & 0.60 \\
\hline & 2 & 0.8 & 0.7 & 0.9 & 0.8 & 0.7 & 0.70 \\
\hline & 3 & 0.6 & 0.9 & 1 & 1 & 1 & 0.60 \\
\hline & 4 & 0.5 & 0.6 & 0.7 & 0.8 & 0.9 & 0.50 \\
\hline & 5 & 0.8 & 0.8 & 0.8 & 1 & 1 & 0.80 \\
\hline & 6 & 0.9 & 0.7 & 0.9 & 0.8 & 1 & 0.70 \\
\hline & 7 & 0.8 & 0.5 & 0.9 & 0.6 & 0.8 & 0.50 \\
\hline & 8 & 0.6 & 0.7 & 0.5 & 0.5 & 0.6 & 0.50 \\
\hline & 9 & 0.4 & 0.7 & 0.8 & 0.7 & 0.7 & 0.40 \\
\hline & 10 & 0.8 & 0.6 & 0.9 & 0.8 & 0.9 & 0.60 \\
\hline & 11 & 0.9 & 0.8 & 1 & 0.9 & 1 & 0.80 \\
\hline & 12 & 0.6 & 0.8 & 0.8 & 0.7 & 0.8 & 0.60 \\
\hline & 13 & 0.7 & 0.9 & 1 & 0.8 & 1 & 0.70 \\
\hline & 14 & 0.8 & 0.7 & 0.8 & 0.7 & 0.9 & 0.70 \\
\hline & 15 & 0.9 & 0.6 & 0.9 & 0.7 & 0.9 & 0.60 \\
\hline & 16 & 0.6 & 0.7 & 0.9 & 0.6 & 0.7 & 0.60 \\
\hline & 17 & 0.5 & 0.6 & 0.9 & 0.8 & 0.8 & 0.50 \\
\hline & 18 & 0.8 & 0.7 & 0.8 & 0.9 & 1 & 0.70 \\
\hline & 19 & 0.6 & 0.8 & 0.9 & 0.7 & 0.9 & 0.60 \\
\hline & 20 & 0.7 & 0.7 & 0.8 & 1 & 0.8 & 0.70 \\
\hline
\end{tabular}

\section{Legend:}

FFR- Testing strategy in a free financial risk environment

AST - Opportunities to test alternative scenarios within a strategy

LFF - Learning from failures

$\mathrm{KSH}$ - Knowledge sharing between students

HSS - Development of hard and soft skills

CND - Computed variable reflecting causal conditions

Table 3 outlines the four antecedent conditions derived from Proposition 2, revealing other three items addressed to the 20 students who has been involved in the practice enterprises (acquiring knowledge to create a start-up, networking opportunities with other practice enterprises and mentorship support), and the outcome: interest to apply for start-up funding programmes, as well as a new variable - ANM (reflecting causal configurations of antecedent conditions) as the result of computing the fuzzy-set values of antecedent conditions, using fsQCA software. 
Table 3. Calibration of qualitative data from Proposition 2

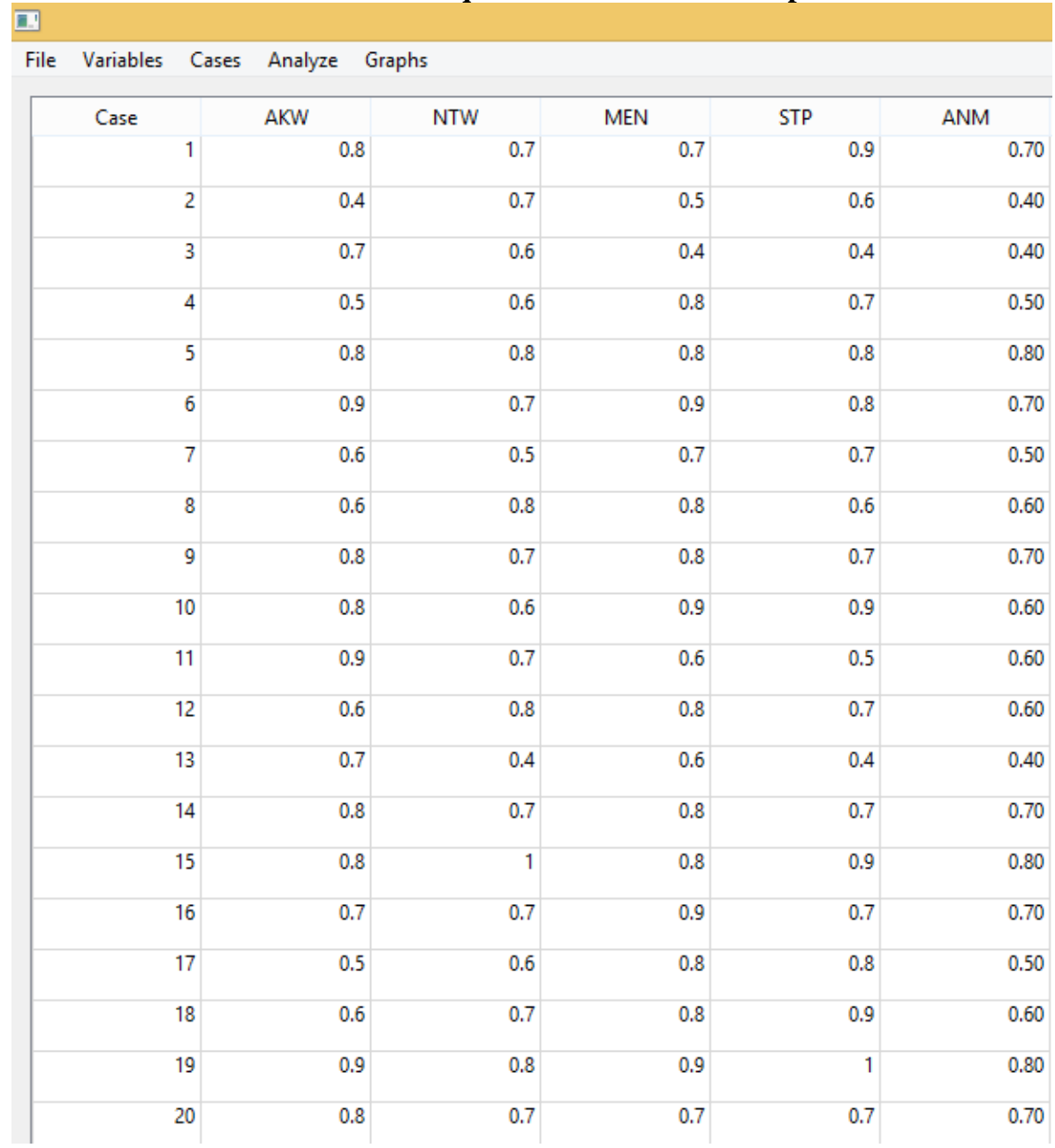

Legend:

AKW - Acquiring knowledge to create a start-up

NTW - Networking opportunities with other practice enterprises

MEN - Mentorship support

STP - Interest to apply for start-up funding programmes

ANM - Computed variable reflecting causal conditions (AKW, NTW, MEN)

\section{Findings}

We have started fsQCA analysis with the visual distribution of fuzzy-sets, to explore if the configurations of conditions lead to the expected outcome. Fuzzyset XY plots allowed us to determine the consistency and coverage scores of the fuzzy sets related to Proposition 1 (Figure 1). The visual representation of cases on 
$\mathrm{XY}$ plot graph reveals that all cases are positioned under the diagonal; the consistency score is 1 (maximum possible), while the coverage score is 0.7167 . The consistency measure should exceed a minimum threshold of 0.75 (Woodside, 2014) to highlight that causal conditions are sufficient for the outcome. Thus, the first proposition: causal configurations of antecedent conditions (FFR, AST, LFF, $\mathrm{KSH}$ ) is a subset of the outcome (HSS). Moreover, CND coverage of the outcome (HSS) is high $(71.67 \%)$.

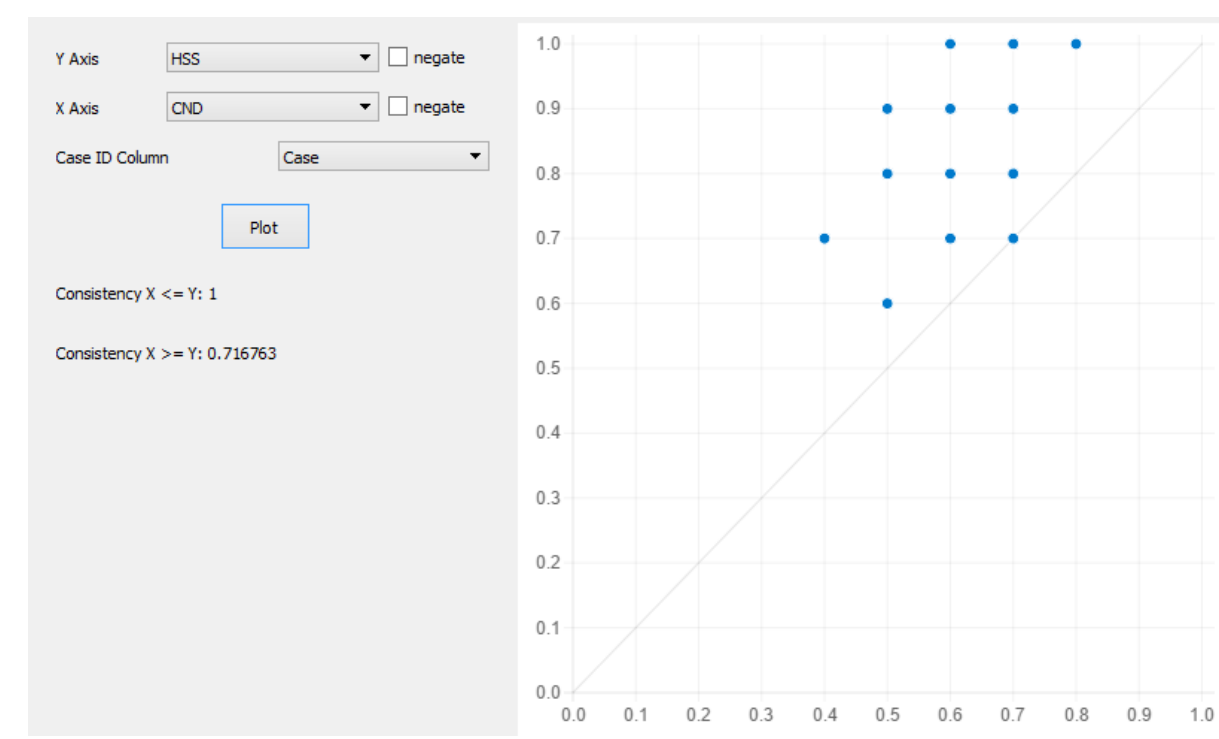

Figure 1. Visual analysis of fuzzy-sets distribution related to the model: HSS = f(FFR, AST, LFF, KSH)

The complex solution provided by the Quine-McCluskey algorithm, in the case of Proposition 1: (AST*LFF*KSH) outlines that opportunities to test alternative scenarios within a strategy, learning from failures and knowledge sharing between students are the most influential predictors of the outcome: development of hard and soft entrepreneurial skills (Table 4).

Table 4. Complex solution, provided by Quine-McCluskey algorithm Model: HSS = f(FFR, AST, LFF, KSH)

\begin{tabular}{lrcc}
\hline \multicolumn{1}{c}{ Complex solution } & Raw coverage & Unique coverage & Consistency \\
\hline AST*LFF*KSH & 0.791908 & 0.791908 & 1 \\
Solution coverage: 0.791908 & & & \\
Solution consistency: 1 & & & \\
\hline
\end{tabular}

A combination of all the antecedent conditions related to Proposition 1 (FFR*AST*LFF* KSH) represents a necessary condition for development of hard and soft entrepreneurial skills (Table 5), as it is the single condition affecting in the great extent the outcome. 
Table 5. Analysis of Necessary Conditions Outcome variable: HSS

Conditions tested

Consistency

0.976879

Coverage

FFR*AST*LFF*KSH

0.938889

It is noteworthy that in the single configuration mentioned above, students' engagement in performing effectively in the practice enterprises is a significant factor for achieving positive levels of both hard and soft skills' development.

In the process of testing Proposition 2, the visual representation of cases on $\mathrm{XY}$ plot graph reveals that most of cases are positioned under the diagonal, some of them being on the overlapping position and only one case below the diagonal (outlier) - Figure 2. The consistency score is 0.99187 (maximum possible), while the coverage score is 0.8472 . Thus, the second proposition: causal configurations of antecedent conditions (AKW, NTW, MEN) is a subset of the outcome (STP). Moreover, ANM coverage of the outcome (STP) is high (84.72\%).

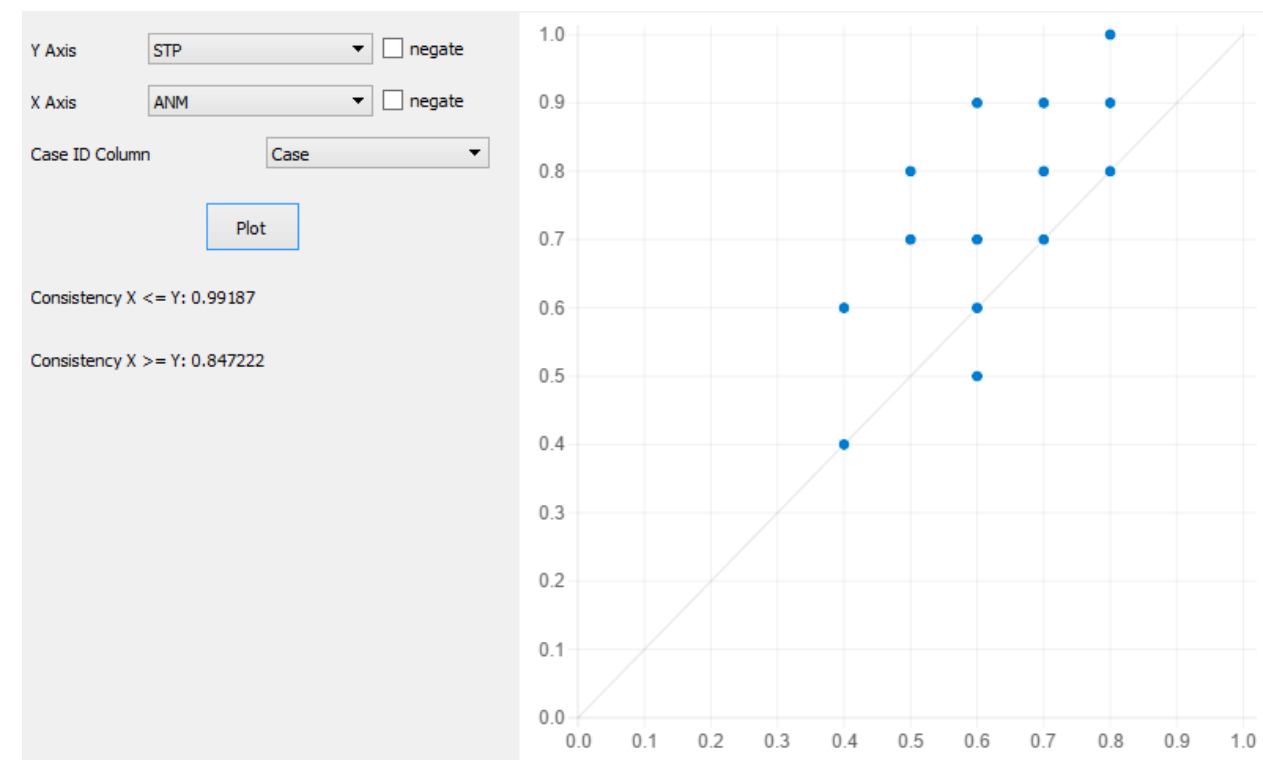

Figure 2. Visual analysis of fuzzy-sets distribution related to the model: STP $=\mathbf{f}($ AKW, NTW, MEN $)$

The complex solution provided by the Quine-McCluskey algorithm, in the case of Proposition 2 outlines two pathways to achieve the outcome (Table 6). The first causal configuration reflects the opportunities of acquiring knowledge to create a start-up and networking with other practice enterprises with main precursors of the interest to apply for start-up funding programmes, while the second causal configuration highlights the opportunities of acquiring knowledge to create a start-up and mentorship support as the main precursors for the same outcome. 
Table 6. Complex solution, provided by Quine-McCluskey algorithm Model: STP $=\mathbf{f}($ AKW, NTW, MEN $)$

\begin{tabular}{lrcc}
\hline \multicolumn{1}{c}{ Complex solution } & Raw coverage & Unique coverage & Consistency \\
\hline AKW*NTW & 0.847222 & 0.765797 & 0.968254 \\
\hline $\mathrm{AKW}^{*} \mathrm{MEN}$ & 0.881945 & 0.795623 & 0.954887 \\
\hline Solution coverage: 0.881945 & & & \\
Solution consistency: 0.933823 & & & \\
\hline
\end{tabular}

A combination of all the antecedent conditions related to Proposition 2 $(\mathrm{AKW} * \mathrm{NTW} * \mathrm{MEN})$ represents a necessary condition for the interest to apply for start-up funding programmes (Table 7), as it is the single condition affecting in the great extent the outcome.

Table 7. Analysis of Necessary Conditions

Outcome variable: STP

\begin{tabular}{ccc}
\hline Conditions tested & Consistency & Coverage \\
\hline AKW $^{*} \mathrm{NTW}^{*} \mathrm{MEN}$ & 0.979167 & 0.865031 \\
\hline
\end{tabular}

It is highly interesting that the second proposition adds value to the research model, as it highlights two configurations and let researchers to explore alternative pathways to reach the outcome.

\section{Conclusions, limitations and further research}

Entrepreneurship education through practice enterprises must primarily target the development of students' hard and soft entrepreneurial skills, on the one hand, and their interest to apply for start-up funding programmes, on the other hand. These outcomes have been addressed in this research by means of three configurational pathways, based on antecedent conditions considered priorities in students' expectations regarding the entrepreneurship education from Faculty of Economics and Business Administration", Dunarea de Jos" University of Galati and Economic College "Virgil Madgearu" of Galati.

The students' perceptions regarding the benefits of entrepreneurial education through practice enterprises have been assessed, with the aim of increasing their interest to apply for the start-up funding schemes. We have chosen fsQCA methodology, as it enabled the translation of research models pillars (testing strategy in a free financial risk environment, opportunities to test alternative scenarios within a strategy, learning from failures and knowledge sharing between students, acquiring knowledge to create a start-up, networking opportunities with other practice enterprises and mentorship support) into causal configurations leading to the desired outcomes.

Using fsQCA in this study provides valuable insights into relationships between entrepreneurial education activities within a higher education institution and an economic college and students' attitudes toward an entrepreneurial career.

One of the main limitations of the paper is the lack of qualitative data, reflecting students' perceptions on the benefits of entrepreneurial education. 
However, the findings from this article spark possibilities for future research. Keeping in mind the variety of entrepreneurial education methods, it seems fruitful to undertake a future qualitative survey of the different approaches that an entrepreneurial university offer.

\section{References}

Bibu, N., Năstase, M. and Gligor, D.C., 2010. The perception over corporate social responsibility in Romania. Review of International Comparative Management, 11(5), pp. 764-778.

Blenker, P., Dreisler, P., Færgemann, H.M. and Kjeldsen, J., 2008. A framework for developing entrepreneurship education in a university context. International Journal of Entrepreneurship and Small Business, 5(1), pp. 45-63.

Carayannis, E.G. and Von Zedtwitz, M., 2005. Architecting gloCal (global-local), real-virtual incubator networks (G-RVINs) as catalysts and accelerators of entrepreneurship in transitioning and developing economies: lessons learned and best practices from current development and business incubation practices. Technovation, 25(2), pp. 95-110.

Esposito, E. and Evangelista, P., 2014. Investigating virtual enterprise models: literature review and empirical findings. International Journal of Production Economics, 148, pp. 145-157.

Fiss, P.C., 2007. A set-theoretic approach to organizational configurations. Academy of management review, 32(4), pp. 1180-1198.

Gundry, L.K., Ofstein, L.F. and Kickul, J.R., 2014. Seeing around corners: How creativity skills in entrepreneurship education influence innovation in business. The International Journal of Management Education, 12(3), pp. 529-538.

Haase, H. and Lautenschläger, A., 2011. The 'teachability dilemma'of entrepreneurship. International Entrepreneurship and Management Journal, 7(2), pp. 145-162.

Honig, B., 2004. Entrepreneurship education: Toward a model of contingencybased business planning. Academy of Management Learning \& Education, 3(3), pp. 258-273.

Jansen, S., van de Zande, T., Brinkkemper, S., Stam, E. and Varma, V., 2015. How education, stimulation, and incubation encourage student entrepreneurship: Observations from MIT, IIIT, and Utrecht University. The International Journal of Management Education, 13(2), pp.170-181.

Kuratko, D.F., 2005. The emergence of entrepreneurship education: Development, trends, and challenges. Entrepreneurship theory and practice, 29(5), pp. 577-597.

Martin, B.C., McNally, J.J. and Kay, M.J., 2013. Examining the formation of human capital in entrepreneurship: A meta-analysis of entrepreneurship education outcomes. Journal of Business Venturing, 28(2), pp. 211-224. 
Nastase, M., Dobrea, R.C. and Valimareanu, I., 2016. Promoting the Entrepreneurial Competencies for School Leadership Development. Revista de Management Comparat International, 17(1), p. 4.

Ragin, C.C., 2009. Redesigning social inquiry: Fuzzy sets and beyond. University of Chicago Press.

Vos, L., 2015. Simulation games in business and marketing education: How educators assess student learning from simulations. The International Journal of Management Education, 13(1), pp. 57-74.

Welsh, D.H., Tullar, W.L. and Nemati, H., 2016. Entrepreneurship education: Process, method, or both? Journal of Innovation \& Knowledge, 1(3), pp.125-132.

Woodside, A.G., 2014. Embrace• perform• model: Complexity theory, contrarian case analysis, and multiple realities. Journal of Business Research, 67(12), pp. 2495-2503. 